\title{
Araç ve Sürücü Kayıt Kontrol Sistemi Uygulaması
}

\author{
İdris SANCAKTAR ${ }^{1}$, Ahmet TURAN ${ }^{2}$ \\ ${ }^{1}$ Elektrik ve Elektronik Mühendisliği Bölümü, Ondokuz Mayıs Üniversitesi, Samsun, Türkiye \\ ${ }^{2}$ Biyomedikal Mühendisliği Bölümü, Samsun Üniversitesi, Samsun, Türkiye \\ ahmet.turan@samsun.edu.tr
}

Received/Geliș: 06.11.2019

Accepted/Kabul: 05.02.2020

\begin{abstract}
Öz: Sürücü ve araç takip sistemlerinde önemli çalışmalar yapılmaktadır. Çalışmalar; Araç kontrol sistemleri, araç takibi, sürücülerin sürüş performansı, sürücü destek sistemleri, sürüş güvenliği ve araç güvenlik sistemleri üzerinde yoğunlaşmıştır. Hız ve fren kontrol sistemleri, aracın sürüş bilgileri, araç donanımının çalışma bilgileri, uzaktan kontrol edilebilme ve sürücü desteği konuları araç donanımlarında yer almaktadır. Böylece araç ve sürücü güvenliği, takibi, çevre temizliği ve ekonomik kazanımlar sağlanmıştır. Yaptığımız çalışmada; bir işletmenin ticari araç ve sürücülerinin takibi için, mikrodenetleyici kontrollü bir sistem tasarladık. Oluşturduğumuz donanım ve yazılım içerikli kontrol ve takip sistemi, araçtan çeşitli verileri kaydetmektedir. Bilgisayara aktarılan verileri analiz eden bir bilgisayar yazılımı oluşturuldu. Cihaz, araçların belirlediğimiz hız üst limitini sınırlayarak kontrol etmektedir. Hız kontrolünde, PID yöntemiyle yumuşak bir hız geçişi yapılmaktadır. Ayrıca sistem, aracın kullanımı esnasında; fren kullanım zamanları, hatalı el freni kullanımı, yakıt kapağı kontrolü, aracın konumuna göre 2-4 çeker geçişi, hararet, fren ve direksiyon hidroliği seviye takibi ve istenmeyen durum tespitinde bunların sesli uyarısını yapmaktadır. Hız, ayak freni ve el freni kullanımı, motor hararet durumu, her saniye için iki aylık zaman dilimini kapsayacak şekilde belleğe kaydedilmektedir. Bu verileri kullanarak, hatalı araç kullanımlarını tespit edecek bir yazılım geliştirildi. Yapılan çalışma araçlar üzerinde başarıyla denendi ve kullanılmaya devam etmektedir.
\end{abstract}

Anahtar kelimeler: Araç hız kontrolü, sürücü sürüş bilgisi, araç donanım takibi, araç takip ve analiz yazılımı.

\section{Vehicle and Driver Record Control System Application}

\begin{abstract}
Important studies are carried out in driver and vehicle tracking systems. Studies; Focused on vehicle control systems, vehicle tracking, driving performance of drivers, driver assistance systems, driving safety and vehicle safety systems. Speed and brake control systems, driving information of the vehicle, operating information of the vehicle equipment, remote control and driver support are included in the vehicle equipment. Thus, vehicle and driver safety, monitoring, environmental cleaning and economic gains have been achieved. In our study, We have designed a microcontroller controlled system for tracking the commercial vehicles and drivers of an enterprise. The hardware and software control and tracking system we create records various data from the vehicle. A computer software was created to analyse the data transferred to the computer. The device controls the vehicles by limiting the upper limit of the speed we set. In speed control, a smooth speed transition is made by PID method. In addition, the system, during the use of the vehicle; brake usage times, faulty handbrake usage, fuel cap control, 2-4 wheel drive according to the position of the vehicle, overheating, brake and steering fluid level monitoring and detection of any undesirable situation makes them sound warnings. The speed, footbrake and handbrake usage, engine overheating status, are stored in memory for each second, covering a period of two months. Using this data, a software was developed to detect faulty vehicle use. The work has been successfully tested on the vehicles and continues to be used.
\end{abstract}

Keywords: Vehicle speed control, driver driving information, vehicle hardware tracking, vehicle tracking and analysis software. 


\section{Giriș}

Sürüş bilgilerinin kaydedilmesi için araçlara monte edilebilen ve taşıtla ilişsili sürüş bilgilerini kaydetmek üzere yapılandırılmış, mobil telekomünikasyon cihazları tasarlamıştır. Bu bilgiler sayesinde trafik kazalarının, araç kaynaklı mı yoksa sürücü kaynaklı mı olduğunu belirlemek de mümkün olacaktır. Araçlarda kara kutu oluşturulmasını sağlayacak bu veriler, sigorta talepleri için kanıt olarak da kullanılabilecektir [1]. Artık araçlarda belirli düzeyde kendi kendine tanılama ve bilgi raporlama yeteneği sağlayan, "Yerleşik Tanılama Sistemleri (On-board diagnostics - OBD)" standart olarak mevcuttur. Bu sistemler; onarım teknisyenlerine, araç sahiplerine, emisyon test kuruluşlarına ve birçok farklı araç alt sistemine ilişkin işlevsel bilgilere, elektronik erişim sağlamaktadır. Frenleme, hız göstergesi, yakıt dağıtımı gibi birçok araç işlevi, elektronik yollarla kontrol edilmekte veya izlenmektedir. Aracın aşırı hızlı, ani hızlanmalı, sert frenlemeyle kullanımı, verimsiz yakıt tüketimi ve maliyetleri artırdığı gibi hava kirliliğine de sebep olmaktadır. Birden fazla sürücü tarafından çalıştırılan araçların, bu tür sorumluluklar açısından takibi, bu verilerin kaydını ve değerlendirilmesini daha önemli hale getirmiştir [2]. Birçok araçta; merkezi kilit sistemleri, açılabilir tavan ve pencereler, motordan bağımsız klima veya yardımcı ssıtma sistemleri, otonom park sistemleri gibi özellikler uzaktan kumanda edilmektedir [3]. Araçların seyahat esnasındaki hız bilgisi üretilen bir sinyal ile uyduya iletilerek, konum bilgilerine göre yerel hız konusunda araç sürücüsüne destek amaçlı uyarı yapılabilmektedir [4]. Araç hız kontrolü genellikle gaz pedalı kontrolü şeklinde yapılmaktadır. Belirlenmiş hız limit değerine ulaşılırken, gaz için pedal basma kuvveti kontrol edilmektedir. Bu kuvvet sonucu hız değerinin hedef değerden daha fazla olması durumunda, hedef değere döndürülmesi için kontrol sağlanmaktadır [5]. Bazı araç kontrol cihazları ile öndeki aracı geçme kontrolü yapabilmektedir [6]. Hatta sürücüleri araçlarla eşleştiren, sürülen mesafeleri, takip edilen rotaları, araçların hareketi, durmaları, toplam sürüş süresi, toplam dinlenme süresi, araç durumu (arıza bakımından), servis aralıkları gibi bilgileri takip edebilen sistemler vardır. Bu veriler maliyetleri azaltırken, araçların performansını doğru bir şekilde takip eder [7]. "Gelişmiş Sürücü Destek Sistemleri'nin (Advanced Driver Assistance Systems ADAS)" amacı, sürücü hatalarının azaltılması, ulaşımdaki verimliliğin artırılması ve çevre kirliliğinde önemli bir düşüş sağlamaktır [8]. ADAS; sürücü iş yükünü azaltma, güvenlik, araç çalışma verimliliği, sürücü rahatlı̆̆ı ve yakıt verimliliğini arttırmada faydalı olmaktadır [9]. Sürücü yardım sistemlerinde araca coğrafi konumlarla ilgili veri aktarımı ve talimatlar sağlanabilmektedir. Sürücü verilen rotadan saparsa uyarı üretilebilmektedir [10]. Aracın konumunu uzaktan izlemek, ateşleme sistemini, kapılarını, 1sıtıcısını, uzaktan açıp kapatmak mümkündür. Sistem, kullanıcının isteğine göre belirli bir aracın yerini izler ve kullanıcıya SMS ile bilgi verir [11].

Bir proje kapsamında yapılan bu çalışmayla, maden sahasında (yer altı ve yer üstü) kullanılan hafif araçların kullanım ömürlerini artırarak maliyetleri azaltacak bir ürün geliştirilmiştir. Araçların kullanıldıkları sahada edinilen tecrübelere dayanılarak, bazı kontrol ve takiplerin yapılmasının maliyetleri düşüreceği düşüncesiyle çalışma yönlendirilmiştir. Yaptığımız çalışma ile özgün tasarlanmış bir kontrol sistemi ve yazılım oluşturduk. Oluşturulan kontrol ve takip sistemi maden işletmesinin hafif yük taşıyan araçlarında uygulamalı olarak çalıştırılmış ve başarılı olmuştur. Her sürücü için araç hız kaydı ve kontrolünün yanı sıra araçlara ait birçok kontrol sağlanmaktadır. Ayrıca sürücü performansını değerlendirmek için bazı araç verileri kaydedildi. $\mathrm{Bu}$ amaçla tasarlanan hız sınırlayıcı ile aracın belirlenen hızı aşmaması için gaz pedalı kontrol edilmiştir. Aynı zamanda, hararet, direksiyon hidroliği, ayak ve el freni kullanımı, depo kapağının yerinde olup olmadığı, aracın 2-4 çeker konumu sürekli olarak kayıt altına alındı. Uygunsuz bir kullanım söz konusu olduğunda da sürücü sesli olarak uyarıldı. Kontrol sisteminin kaydettiği verileri bilgisayarda veri tabanına aktararak, gerekli istatistikî bilgileri raporlayan bir bilgisayar yazılımı gerçekleştirilmiştir. 


\section{Materyal ve Metot}

Çalışmamızda; 5 adet 16F877 ve 1 adet 18F4550 mikrodenetleyici, RFID kart okuyucu, WiFi alıcı vericiler, 4 adet $I^{2} C$ bellek, ses kayıt ve çalma entegresi, RTC (Gerçek zamanlı saat takvim) entegresi ve 2 adet veri seçme entegresi kullandık.

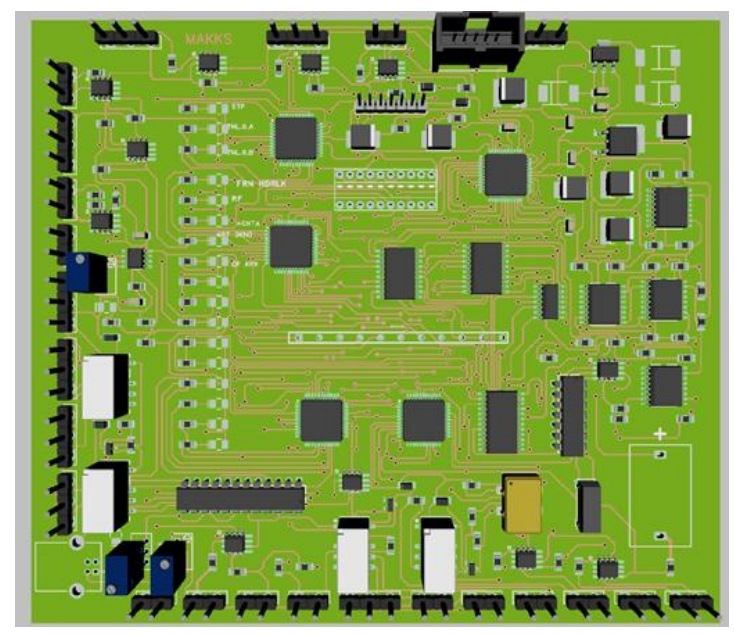

Şekil 1. Kontrol sisteminin elektronik devresi

Mikrodenetleyiciler; aracın kullanımı esnasında birçok verinin okunarak belleklere kaydedilmesi ve araçtan gelen hız verisi, yazılımda belirlenen üst limit değerine ulaştığında aracın yavaşlatılması için kullanıldı. Şekil 1'de görülen kontrol cihazının kaydettiği veriler, oluşturulan yazılım ve donanımla bilgisayara aktarıldı. Kontrol cihazının kaydettiği verilerle ilgili çeşitli analizler ve grafikler oluşturmak için bilgisayar yazılımı oluşturuldu.

\subsection{Kontrol sisteminin yapısı ve araç üzerinden okunan verilerle yapılan kontroller}

Şekil 1'de gösterilen “Araç ve Sürücü Takip ve Kontrol Sistemi” için oluşturduğumuz elektronik devrede 5 adet mikrodenetleyici kullandık. Şekil 2'de görülen şemadaki M1 ve M4 mikrodenetleyicileriyle (16F877); araç hız bilgisi, el ve ayak fren durumu bilgisi, hararet, depo kapağı, firen ve direksiyon hidroliği ve kontak anahtarı durumu bilgisini okumak için kullandık. Aynı zamanda bu kontrollerle ilgili led göstergelerde durum ikazları oluşturuldu. M3 mikrodenetleyici ile (16F877); araç konumuna göre WIFI kontrolüyle 2/4 çeker seçimi, personel kart okuyucu ve sistem kapama durumları gerçekleştirildi. M2 mikrodenetleyicisi ile (16F877); hız göstergesinde okunan hız verisi ile gaz pedalinden okunan hızlanma isteğini karşılaştırarak ECU (Elektronik Kontrol Ünitesi)'ya hızlanma istek durumu verisini biz gönderdik. Böylece sistem devrede olduğunda araç hızlanma isteği, kontrol sistemi tarafindan gerçekleştirildi. M5 mikrodenetleyicisi (16F877); sürücüyü oluşan olumsuz durumlarda sesli uyarmak için kullanıldı. M6 mikrodenetleyicisi ile (18F4550); diğer mikrodenetleyicilerin koordinasyonu, verilerin bellek kaydı ve bilgisayara aktarılması işlemleri yapıldı. Araçlarda aşağıda ifade edilen kontroller gerçekleştirildi.

\section{Fren ve direksiyon hidroliği kontrolü;}

Fren ve direksiyon hidrolik kontrolü için gerekli bilgiyi araç sensörlerinden almayı tercih etmedik. Hidrolik seviyeleri, sensörlerin bozulma ihtimali değerlendirilerek, depoların dış yüzeylerine yerleştirilen sıvı seviye ölçerler yardımıyla (ultrasonik algılayıcı hidrolik kutusuna bitişik tutularak) ölçüldü. Seviye ölçer üzerindeki anahtarlarla ayarlanan seviyenin altına düşüldüğünde, bunu belirten sayısal bir veri üretildi. 


\section{Depo kapă̆ı kontrolü;}

Araçlar yakıt aldıktan sonra depo kapağının açık kalmaması veya yakıt alma dışında kapağın açılıp açılmadığının kontrolü amaçlanmıştır. Bunu için depo kapağının altında, depo içine doğru, elektriksel izolasyonu yapılmış bir fotosel yerleştirildi. Kapağın açık olması durumu, sensörden gelen analog veri ile algiland.

\section{Hararet kontrolü;}

Motorun üzerine yerleştirilen sıcaklık algılayan bir termik eleman yardımıyla analog veri olarak algiland1.

\section{Fren basma zamanlarının ölçümü;}

Her 1sn zaman aralıkları için, araç fren pedalına basılma durumu algılandı. Bu veri doğrudan fren sisteminden okundu.

\section{El freni kontrolü;}

Hız değeri sıfır değilken yani araç hareket halindeyken el freninin çekili kalma durumları algılandı. Her 1sn lik zaman dilimlerinde el freni kontrol edildi. Hiz verisi de kontrol edilerek, hareket halindeyken çekili ise kaydedildi ve sesli uyarı mesajı oluşturuldu.

\section{Araç çekiş gücü için 2/4 çeker tercihi kontrolü;}

Maden sahası içerisinde, yeraltında çalışacak araçların 4 çeker şekilde, yer üstünde ise 2 çeker şekilde çalışması istenmektedir. Bunun için tünel girişine yerleştirdiğimiz iki adet radyo vericisi algılanarak, aracın 2/4 çeker değişiminin yapılması sesli olarak uyarılmakta ve bunun yapılmaması durumu kaydedilmektedir.

\section{Sistem aç-kapa kontrolü;}

Uzaktan kumanda kullanarak, kapsama alanındaki tüm araçlarda aynı anda kontrol sistemini açmak veya kapamak mümkündür. Sistem kontrolü için sürücüye ait bir RFID kart kullanıldı. Ayrıca araca monte edilen kontrol sistemindeki kart okuyucuya yetkili kart takıldığında, sadece o aracın kontrolleri açılıp kapatılabilir.

\section{Veri Kayıt kontrolü;}

Gerçek zamanlı elde edilen veriler sistem içinde bulunan belleklere kaydedildi. Veriler iki ay boyunca her 1sn'lik zaman dilimleri için veriyi saklayacak şekilde kaydedildi. İki ay sonunda eski tarihli verilerin üzerine sırayla yazılacak şekilde döngü oluşturuldu.

\section{Sesli Uyarı sisteminin Kontrolü;}

Sürücüyü çeşitli durumlarda uyarmak üzere sesli uyarı sistemi tasarlandı. Oluşan durumlarda seslendirilmek üzere aşağıdaki ses kayıtları yapıldı ve o durum oluştuğunda seslendirildi;

"Fren hidroliği seviyesi düşük"

"Direksiyon hidroliği seviyesi düşük"

"Hararet yüksek"

"Yakıt depo kapağı yerinde yok" 
"Hareket halinde el frenini çekmeyiniz"

"Hız limitini aştınız"

"İki çekere geçiniz"

"Dört çekere geçiniz"

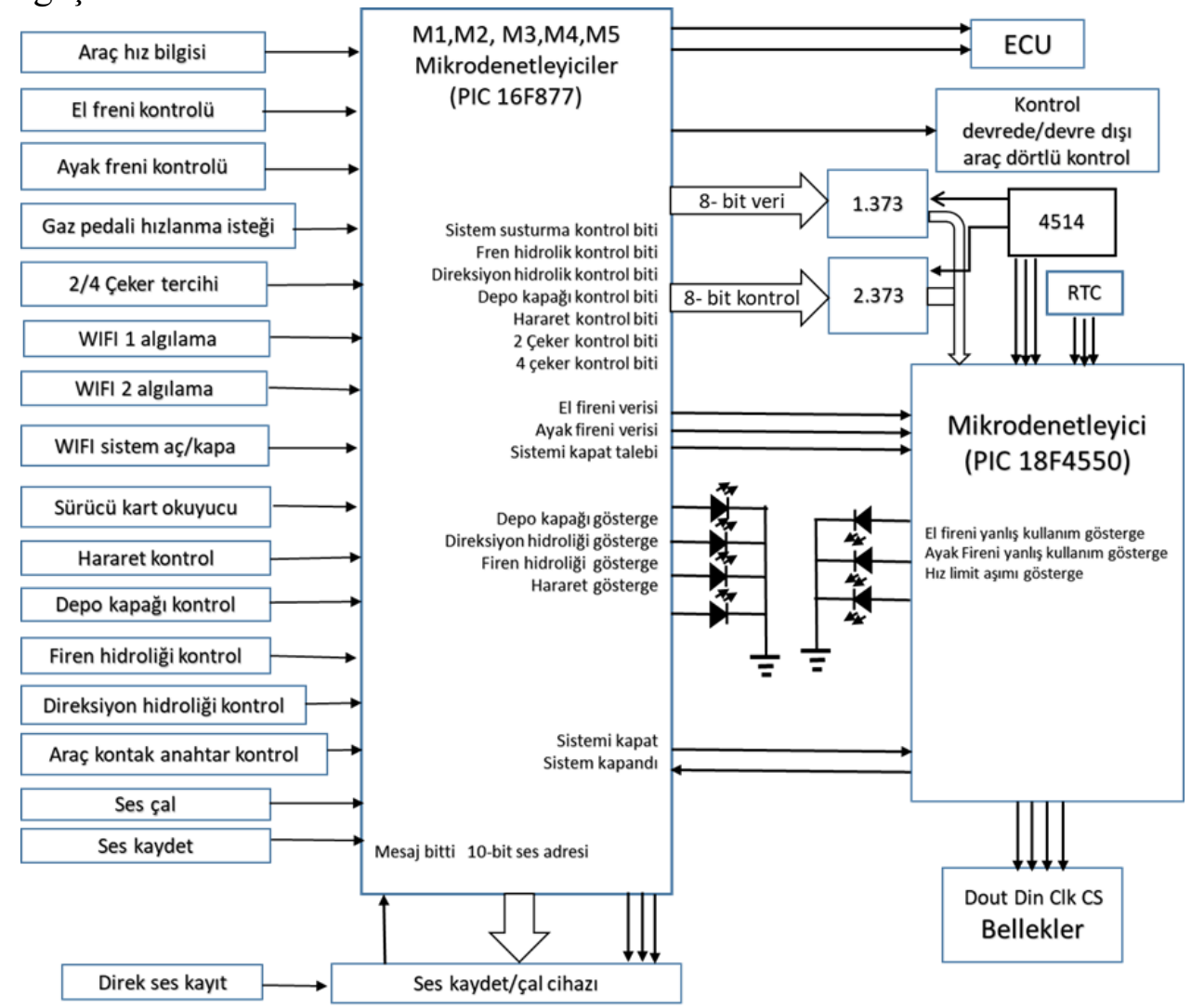

Şekil 2. Araç ve sürücü takip ve kontrol sistemi cihazı şeması

\subsection{Araç hız kontrolü}

Araç hız kontrolü için, hız gösterge telinden aracın sürekli olarak hız verisini okuduk. Okunan veri hız üst limit değerine yaklaştığında, araç hızı kademeli yani yumuşak şekilde (sert değil) limit hız değerinin altına düşürüldü. Bu işlem yapılırken PID kontrol gerçekleştirildi. PID aslında bir kontrol geri bildirim mekanizmasıdır. Bir PID denetleyici ölçülü bir süreç içinde değişen ve istenilen ayar noktası ile arasındaki farkı alarak bir "hata" değerini hesaplar. Kontrol giriş ayarı yapılarak bu hatanın en aza indirilmesi sağlanır [12]. Biz de limit hıza yaklaştıkça mevcut hızla limit hız arasındaki farkı her seferinde hesaplayarak gaz sistemine buna uygun müdahalenin yapılmasını sağladik.

\section{$H_{1 z} \leq$ limit h1z}

Çalışmamızda hız verisi okunduktan sonra, araç gaz pedali ile beyin arasına giren kontrol cihazı sayesinde, araç hız değişiminin oluşturulan elektronik kontrol devresiyle yapılması tasarlandı. Şekil 3'de şeması görülen hız kontrol devresiyle, gaz pedalinin kontrolü ele alınmaktadır.

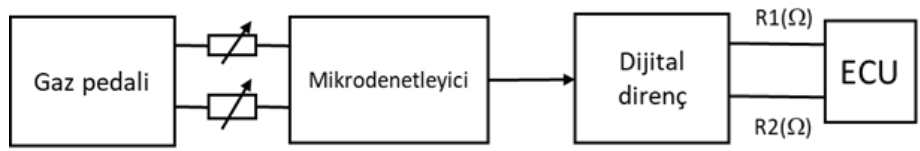

Şekil 3. Araç hız kontrol şeması 
Aracın ani hızlanmasını kesip, yumuşak duruşu sağlamak için aşağıdaki hareket denklemini kullanarak PID kontrol yaptık. Kontrol teorisinde yeni teknikler geliştirilmiş olmasına rağmen, Şekil 4'de blok şeması verilen PID denetleyiciler kontrol mühendisliği problemlerinde hala yaygın olarak kullanılmaktadır.

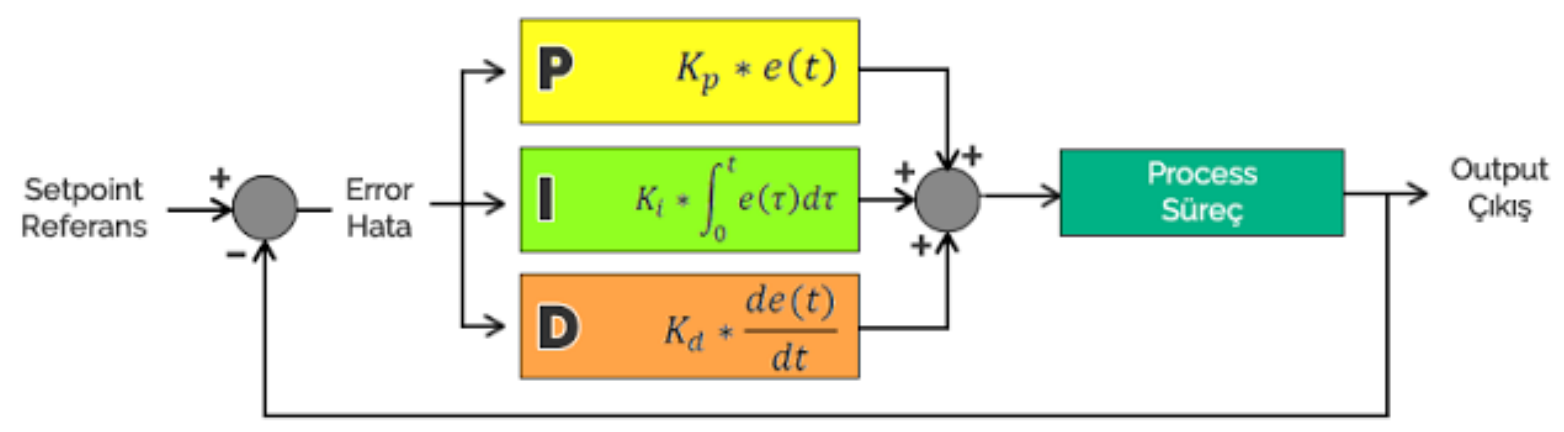

Şekil 4. PID koltrol açık şeması içeren kontrol sistemi [13]

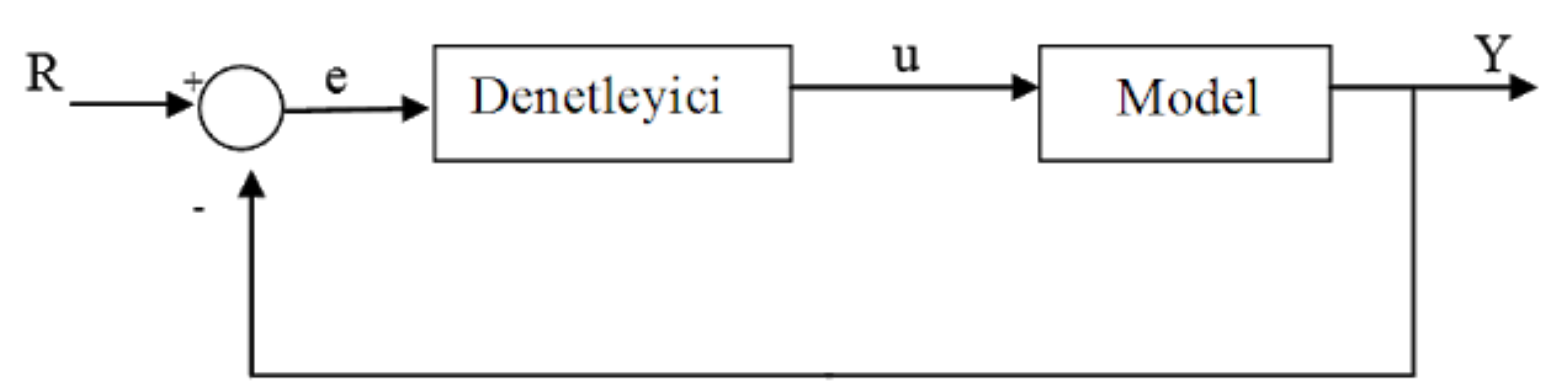

Şekil 5. PID kontrolör içeren kapalı çevrim kontrol sisteminin blok diyagramı [13].

Şekil 5'de görülen blok şemada; e: hata işareti, u; etkiyen işaret, model; kontrol edilen sistem, denetleyici; modelin uyarılmasını sağlayan ve bütün sistem davranışını denetleyen bölüm şeklinde tanımlanmıştır. Değişken(e), izleme hatasını temsil eder, istenen değer (R) ile gerçek çıkış (Y) arasındaki farktır. Hata sinyali (e) PID denetleyiciye gönderilir, PID denetleyici bu hatanın hem integralini hem de türevini hesaplar. Kontrolörden çıkan (u) etkiyen işareti, denklem 1'de görüldüğü gibi hatanın büyüklüğünün $\left(K_{p}\right)$ oransal kazancı katı, hatanın türevinin $\left(K_{d}\right)$ katı ve hatanın integralinin $\left(K_{i}\right)$ katlarının toplamına eşittir.

$$
u=K_{p} \cdot e+K_{i} \int e d t+K_{d} \cdot \frac{d e}{d t}
$$

$\mathrm{Bu}(\mathrm{u})$ işareti modele gönderilir ve yeni çıkış $(\mathrm{Y})$ işareti elde edilir. $\mathrm{Bu}$ yeni çıkış işareti $(\mathrm{Y})$ algılayıcıya tekrar geri gönderilir, böylece yeni hata sinyali(e) bulunur. Denetleyici yeni hata işaretini alır, integral ve türev değerlerini hesaplar.

Çalışmamızda hız değerini okuyup referans hız değeriyle arasındaki farkı elde ederek bu sisteme uyguladık. Hızımız referans hız değerine belli bir oranda yaklaştığında PID kontrolü devreye girmektedir. Eğer referans hız değeri bir şekilde aşılmışsa hızlanma isteği gaz pedali kontrol edilerek tamamen kesilmektedir. Şekil 6'daki grafikte görüldüğü gibi hız sınırına $\Delta V$ kadar yaklaştıkça limit hız değeri geçilemeyecek şekilde grafikteki gibi bir hız uygulaması yapılır. Hız, kademeli düşürülerek limit değerin aşılmaması ve aracın ani hız kesimleri yapılmadan hareket etmesi sağlandı. 
Sürücü gaza ne kadar yüklense de aracın hızlanması engellenip kontrol altına alınmaktadır. Araç bir sebeple hızlandırılmak istense de buna limit değer üzeri için izin verilmemektedir. Araç hangi viteste olursa olsun gaz pedal konum kontrolünden ECU'ya hızlanma değişimi kontrol devresi tarafından verildi. Bu veri limit aşım isteği oluşunca devre tarafından limit değerine yaklaşacak şekilde araç beynine iletilir.

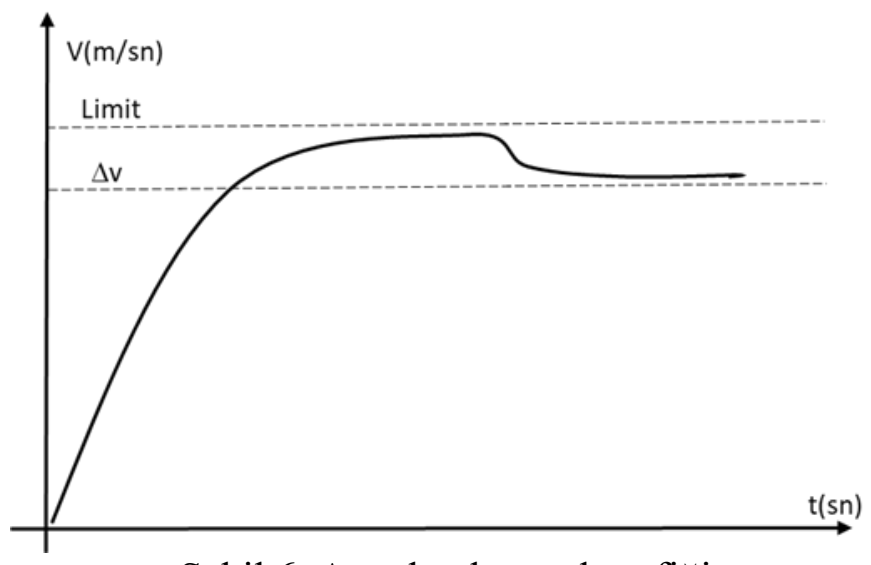

Şekil 6. Araç hız kontrol grafiği

Hız aşım durumunda ayrıca sesli hız aşımı uyarısı mesajı oluşur. Araç yokuş aşağı inerken, aracın gaz pedalından hızlanma isteği gelmezse bile hızlanabilir. 1sn aralıklarla hız verisi kaydedildiğinden bu tür durumlar yazılım analizinde ortaya çıkar.

\subsection{Araçlardan okunan verilerin kaydedilmesi}

Araca bağladığımız sensörlerden alınan veriler 1 saniye aralıklarla kaydedilmektedir. Araçtan algılanan anlık hız verisini kaydetmek için 1 bayt'lık bellek alanına ihtiyaç vardır. Toplanan diğer tüm veriler için sadece iki durum söz konusu olduğundan, bu veriler bit olarak $(0,1)$ kaydedilebilirler. $\mathrm{Bu}$ verilerle birlikte her saniye için kaydedilecek 2 bayt'lık veri oluşmaktadır. Basit bir hesapla bir gün için kaydedilecek olan saniye adedi;

$24 * 60 * 60=86.400 \mathrm{sn}$

Her bir saniye için de 2 bayt'lık veri kaydedileceğinden, bir gün için;

$86.400 * 2=172.800$ bayt veri kaydedilecektir.

60 günlük süre için bu verileri kaydetmek üzere 4 adet $\mathrm{I}^{2} \mathrm{C}$ bellek kullandık. Bu belleklerden iki tanesi tek, diğer iki tanesi ise çift aylar için kullanılmıştır. Araç hız bilgisi bir belleğe, diğer tüm veriler ise diğer belleğe kaydedilmektedir. Her gün için belleğin bir sektörü kullanılmıştır ve her saniye için okunan hız verisi, bu sektöre sırayla kaydedilir. Aynı şekilde diğer veriler de, diğer belleğin aynı numaralı sektörüne kayıt edilir. Her gün başlangıcında ilgili sektör silinir. Böylece aynı sektöre tekrar sıra gelmesi için 2 ay geçmesi gerekir. Bellekte her sektörün ilk alanına RTC entegresinden alınan tarihi kaydettik.

\subsection{Kontrol sistemi tarafından elde edilen verilerin bilgisayara aktarımı ve yazlımla analizi}

Oluşturduğumuz sistemde belleklere kaydedilen veriler, istenildiğinde bilgisayara aktarılabilmektedir. Bu amaçla USB protokolü kullanılıp belleklerde kayıtlı olan veriler okunarak bilgisayara aktarılmakta ve MySQL veri tabanına kaydedilmektedir. Belleklerden bir tanesinin ilk sektörüne aracın plakası girilmektedir. Bilgisayar yazılımı ile bağlantı kurulduğunda, yazılım devreden gelen plakayı veri tabanında arar; bulamazsa yeni kayıt olarak ekler, bulursa da o kaydı 
seçerek verileri ekler. Her sektörün ilk alanları ve kayıtlı olan tarihler okunarak bilgisayar yazılımında listelenir. Kullanıcı istediği tarihi seçerek, o tarih için kayıtlı olan tüm verileri kontrol cihazının belleklerinden, USB üzerinden alır ve MySQL veri tabanına kaydeder. Kayıtlı verilerden istenilen tarih seçilerek ilgili bilgilere ulaşılır ve detaylı bilgiler sınıflandırılıp ekranda kolay anlaşı1ır şekilde gösterilir.

\section{Bulgular ve Tartışma}

Araca ait veriler, algilayicilar ve mikrodenetleyiciler sayesinde elde edilerek $\mathrm{I}^{2} \mathrm{C}$ belleklere yazılmaktadır. Hız sınırlayıcı sürekli kontrol edilirken, diğerleri 1 sn aralıklarla kontrol edilmektedir. Tüm veriler 1 saniye aralıklarla belleklere yazılmaktadır. Hangi belleğin hangi adresine verinin yazılacağı, kullanılan 18F4550 mikrodenetleyicisi tarafindan belirlenmektedir. Sürücünün uyarılması gereken durumlarda, ses kayıt entegrelerine daha önce kaydedilen sesler, oluşan duruma göre aracın ses sistemine iletilmektedir. Aynı anda oluşan uyarı sayısı birden fazla ise yazılım bu uyarıları sıraya koyarak işleme almaktadır. Böylece aynı anda farklı seslerin işlenmesi veya biri bitmeden diğerinin başlaması gibi istenmeyen durumların önüne geçilmiştir. Kullanılan 16F877 mikrodenetleyiciler bir veya daha fazla işlevi bağımsız şekilde yerine getirmektedir. 18F4550 mikrodenetleyicisi ise diğerlerinden gelen verileri sirayla ister ve belleklere kaydeder.

18F4550 aynı zamanda USB üzerinden bilgisayar ile de haberleşmeyi sağlamaktadır. Devre USB ile bilgisayara bağlandığında, yaptığımız yazılım ile iletişime geçer ve bu yazılımdan gelen komutlar devre tarafından işleme alınır. Her devreye takılı olduğu aracın plakası bu yazılım tarafından yazılır ve daha sonra her bağlantı sağladığında bu plaka yazılım tarafindan okunur. Bilgisayardaki bu yazılım aynı zamanda MySQL veri tabanı ile bağlantıyı sağlamaktadır. MySQL veri tabanı aracın plakasını ve bu plakaya ait diğer tüm verileri saklamaktadır. Her araca ait her gün için bir kayıt eklenir. Günlük kayıt içerisinde kaydedilen tüm veriler birer saniyelik aralıklarla kaydedilir. Devre USB ile bilgisayara bağlandığı anda plaka okunur ve veri tabanında da bu kayıt otomatik olarak seçilir, eğer plaka kayıtlı değilse eklenir. Böylece bir araca ait verilerin başka bir araca ait kayıtla karıştırılmasının önüne geçilmiş olunur.

Bilgisayar ile bağlantı sağlandığında aracın plakası okunur ve "Kayıtlı Günleri Oku" butonuna basıldığında araçta kayıtlı olan günlerin listesi 18F4550 tarafindan yazılıma gönderilir. $\mathrm{Bu}$ günlerden istenen seçilerek "Seçili Günü Oku" butonuna basıldığında ise o güne ait tüm kayıtlar bilgisayara aktarılarak MySQL veri tabanına kaydedilir. Kaydedilen bu verilerden; tüm bilgiler veya hatalı ve istenmeyen durumlar listelenir ya da grafik olarak gösterilebilir. Elde edilen ve raporlanan bu veriler sayesinde hangi sürücülerin hangi hataları yaptığı belirlenebilir. Böylece ilgili sürücüler uyarılabilirler. Zaten anlık olarak sesli uyarılar da yapılmaktadır. Hatalı kullanıma ait kayıtların tutulduğunun bilinmesi bile başlı başına caydırıcılık sağlamaktadır. Burada bahsedilen proje ile gerçekleştirilen elektronik devre, gömülü yazılımlar ve bilgisayar yazılımı tasarlanarak gerçekleştirilmiş ve uygulamaya konmuştur. Projenin sağlıklı ve doğru bir şekilde çalıştığı test edilerek gözlemlenmiştir. Asıl hedef olan maliyetlerin düşürülmesi için istenen sonuçlara da ulaşılmıştır.

\subsection{Verilerin değerlendirilmesi}

Araç kontrol cihazının kaydettiği veriler bilgisayara aktarılarak incelenmektedir. Şekil 7'de verileri inceleyen programın arayüzü görülmektedir. $\mathrm{Bu}$ ekranda birçok araç için kaydedilmiş plaka ve tarihler yer almaktadır. Bu seçenekler sonrası kaydedilen hız, ivme, fren ve $2 / 4$ çeker bilgileri ve diğer veriler bölümleri bulunmaktadır. 
$\mathrm{Bu}$ ekranda hız değerleri görülmektedir. Yazılımda araç plakası ve tarih seçilerek saniye seviyesinde araç hızı gözlenebilmektedir. Şekil 7'de görüldügü gibi araç hızı bazı zamanlar hariç limit değerinin üzerine çıkmamaktadır. Fakat bazı zaman aralıklarında, kontrol sisteminin izin verdiği hız seviyesinin üzerine çıktığı yerler tespit edilmiştir. Normalde araç viteste giderken sistem buna müsaade etmemektedir. Fakat sürücü yokuş aşağı inerken araç hızını limit değerin üzerine çıkartabilmektedir. Sistem buna müdahale edemese de bu durum hem kaydedilmekte hem de sesli olarak "limit hızı aştınız" şeklinde sürücüyü uyarmaktadır. Veriler analiz edilirken saniye başına hız değeri gösterilebilmektedir.

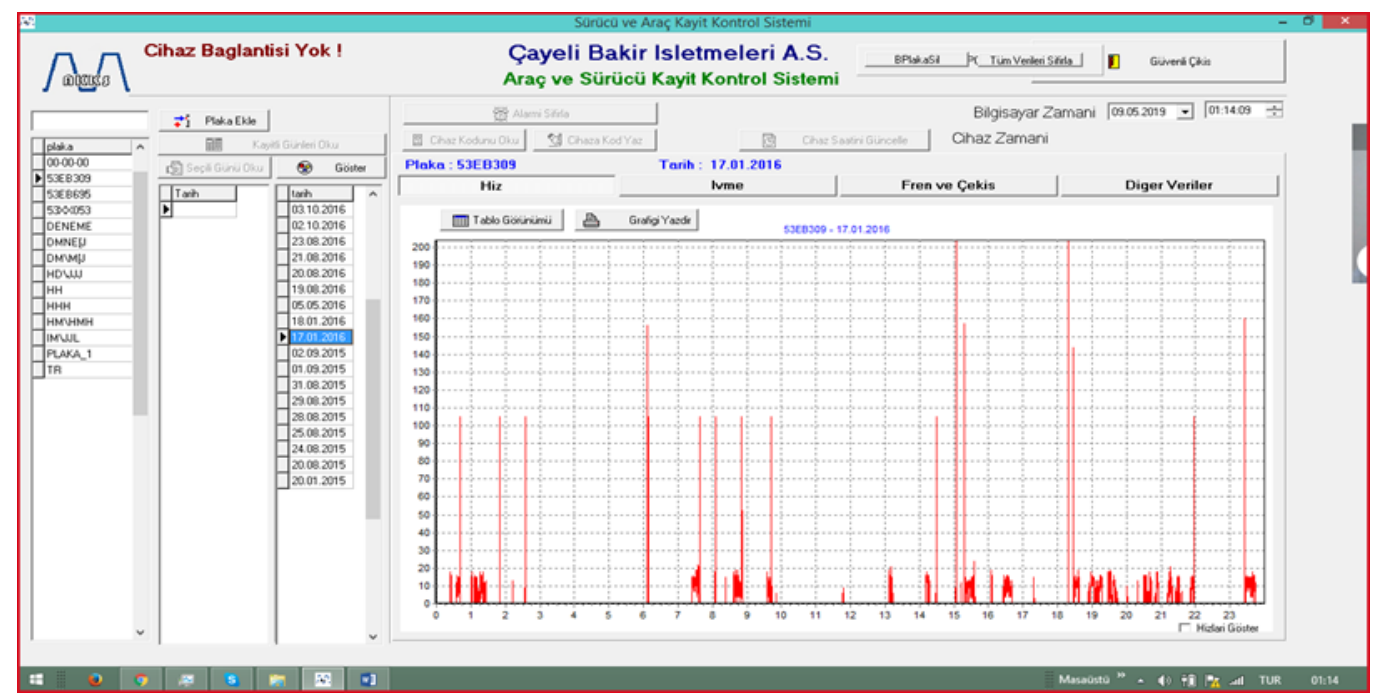

Şekil 7. Araç takip cihazı veri analiz yazılımı ekran görüntüsü

Şekli 8' de görüldüğü gibi analiz esnasında zaman ekseni büyütülüp küçültülebilir. Böylece zaman ekseninde araç verileri daha detaylı görülebilmektedir.

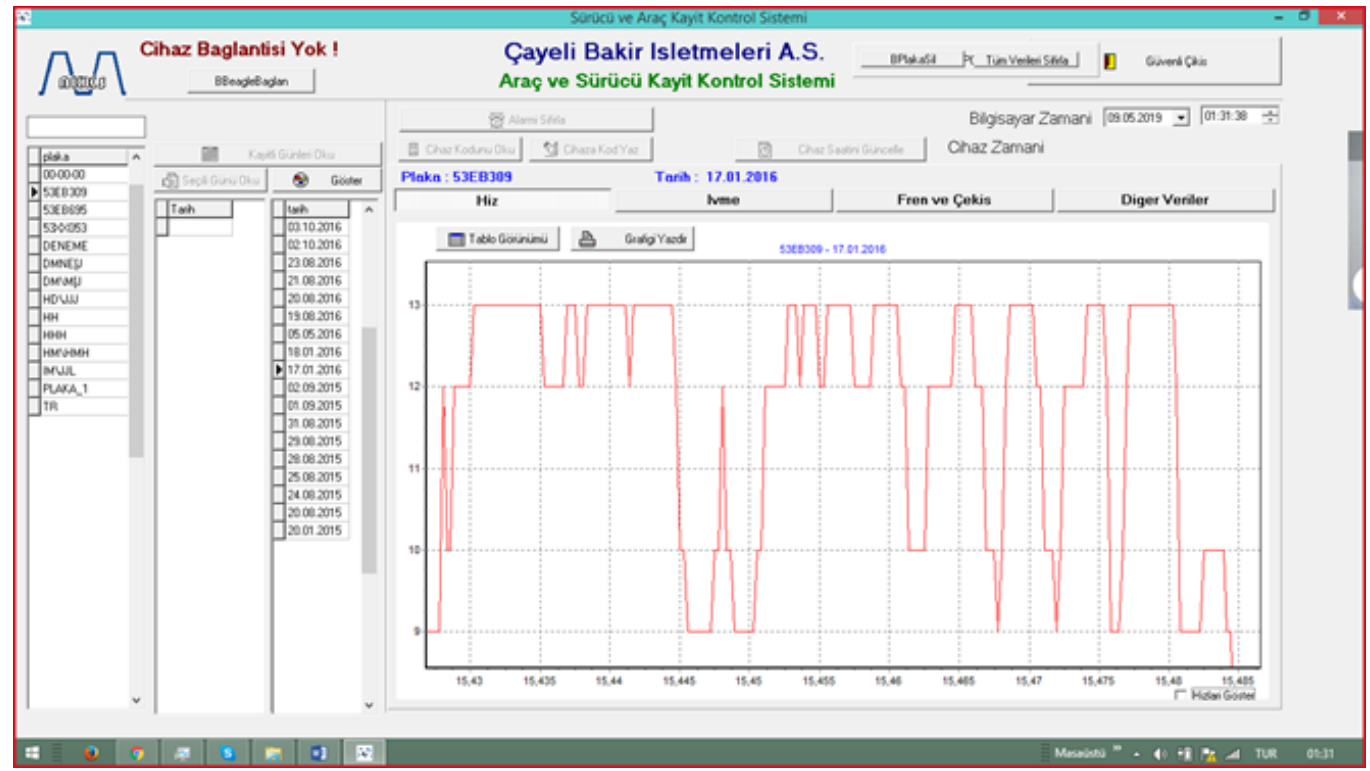

Şekil 8. Araç takip cihazı veri analiz yazılımı ile kayıtlı, hız verileri ve grafikleri

Aracın sürüş şekliyle ilgili sürücü performansını değerlendirmek için kalkış ve duruş hareketlerini gözlemek amaciyla aracın ivmesini izledik. Böylece sürücünün ani hılanma ve frenleme davranışları tespit edildi. Şekil 9'da ivme grafiği görülmektedir. 
Sürücülerin bulundukları konuma göre 2-4 çeker tercihini, ayak freni kullanım sıklığını ve araç hareket halindeyken el freni çekilme durumunu kontrol sistemiyle takip etmiştik. Kaydedilen veriler oluşturulan yazılımla incelenerek sürücü performansı gözlendi.

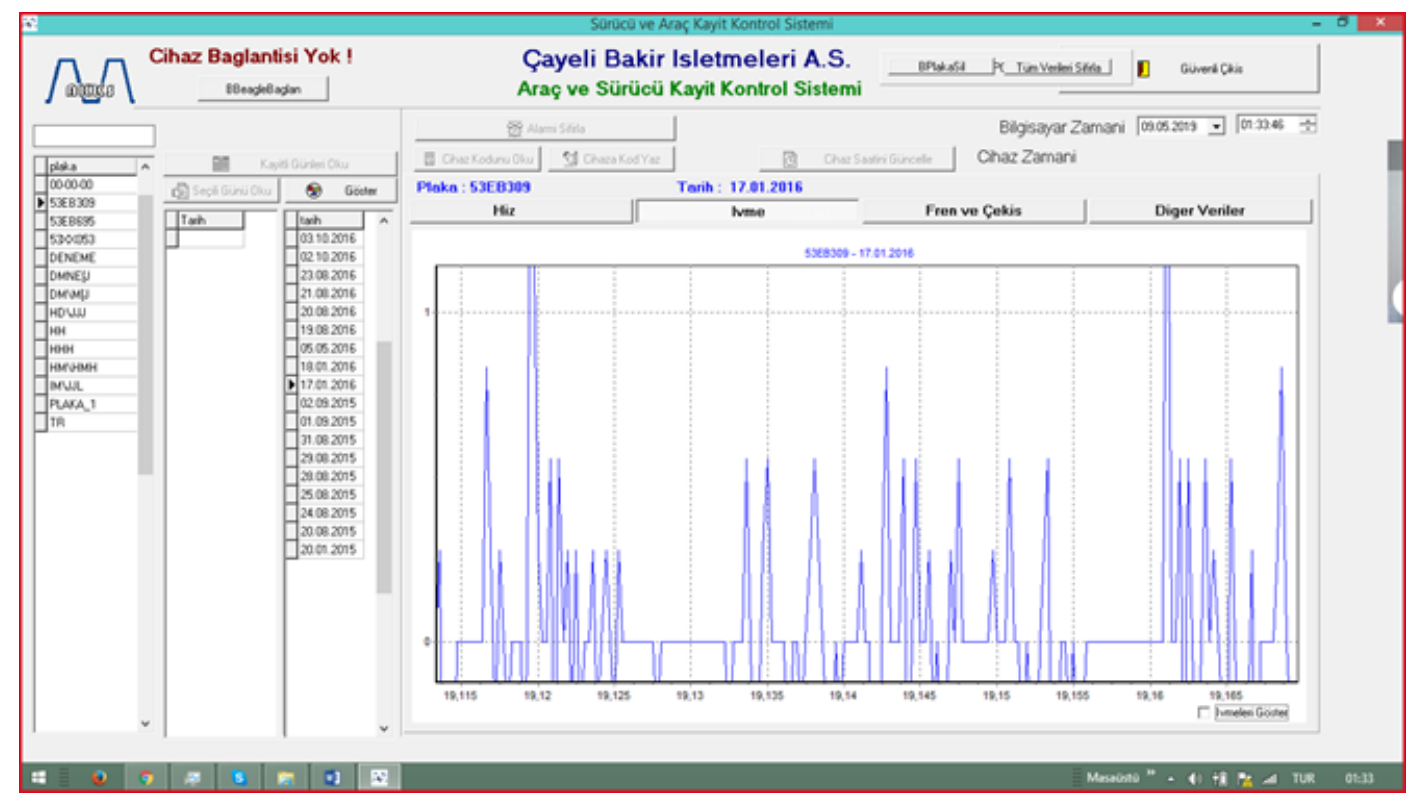

Şekil 9. Araç takip cihazı veri analiz yazılımı ile kayıtlı, ivme verileri ve grafikleri

Şekil 10'da plakası seçilen aracın seçilen tarihte ayak freni basılma zamanları, el freni çekili kalma zamanları ve 2-4 çeker olma durumlarındaki aksaklıklar, oluştukları zamanlarda tespit edilerek kaydedildi ve tabloya aktarıld.

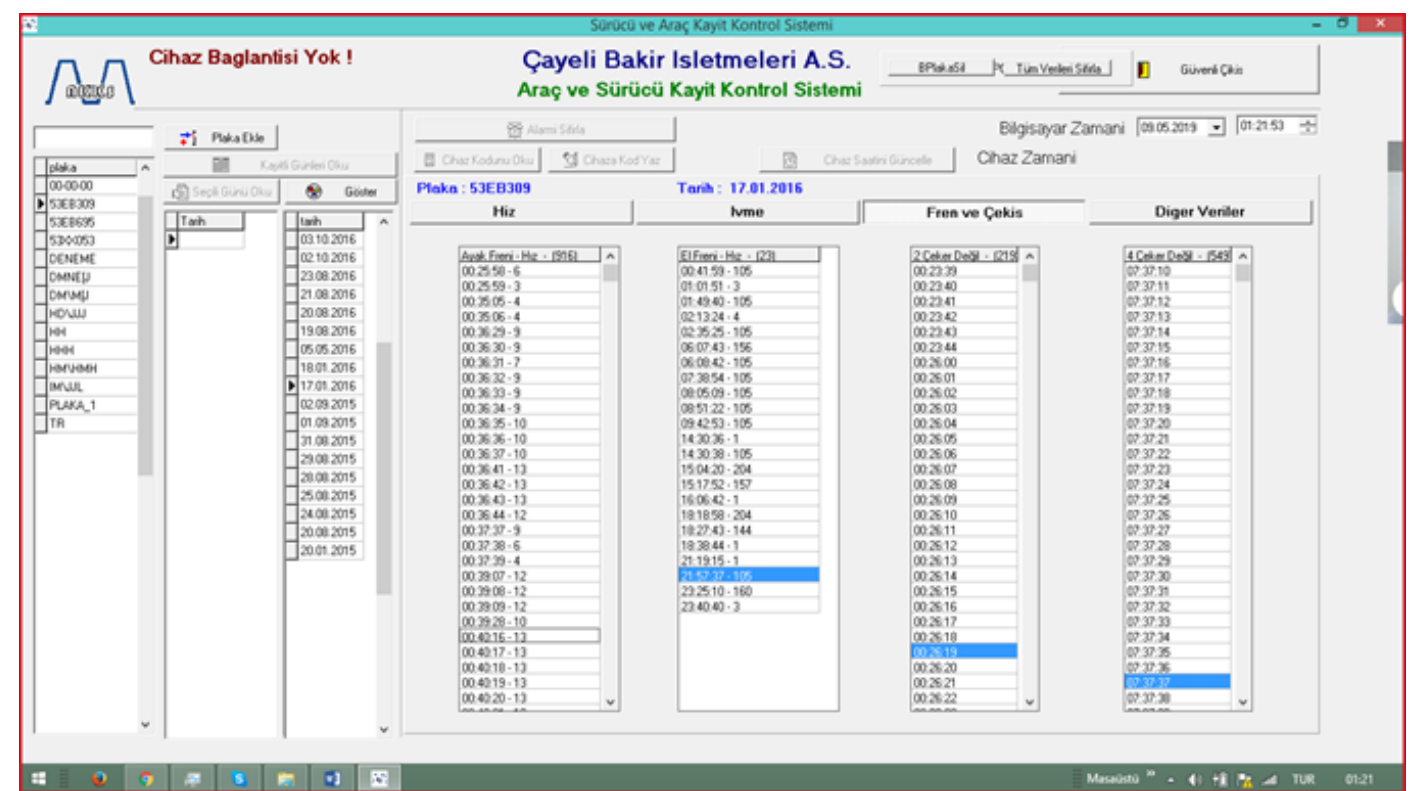

Şekil 10. Araç takip cihazı veri analiz yazılımı ile kayıtlı; el ve ayak frenine basıldığı zaman ve hız değeri, 2-4 çeker olması gerektiği zaman verileri.

Ayrıca Şekil 11'de görüldüğü gibi; fren ve direksiyon hidroliği seviyesi, hararet durumu, depo kapağının açık kalma zamanları sistem tarafından kaydedildi ve oluşma zamanlarıyla birlikte tablolara aktarıldı. 


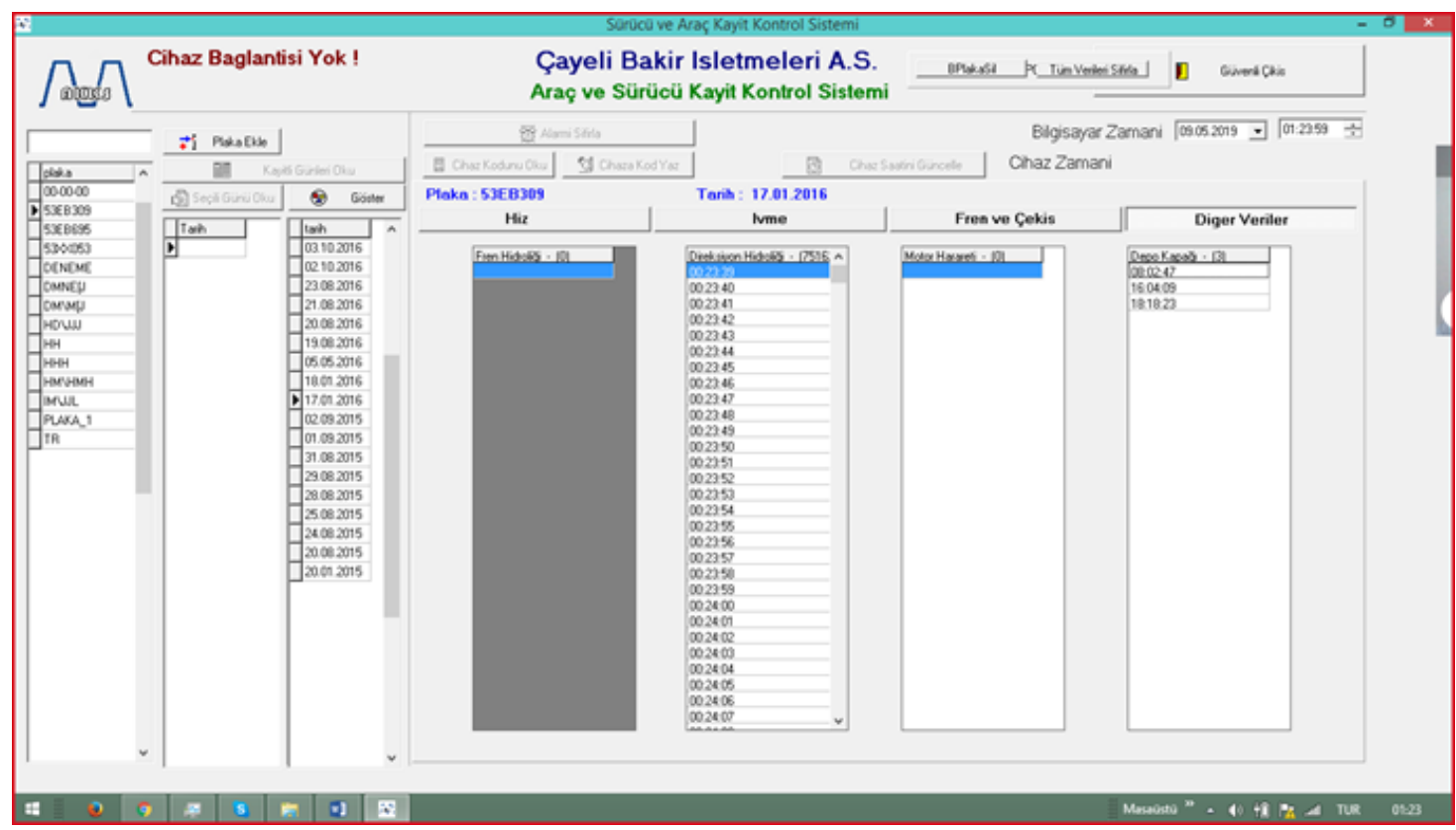

Şekil 11. Araç takip cihazı veri analiz yazılımı ile kayıtlı, fren ve direksiyon hidroliği, hararet ve yakıt depo kapağı kontrollerinin kayıtları.

\section{Sonuç}

Yapılan çalışma her türlü araçta kullanılacak şekilde tasarlandı. Ayrıca tasarladığımız araç ve sürücü takip sistemi isteğe bağlı geliştirilebilir şekildedir. Oluşturulan sistem bir maden işletmesinin araçlarında test edildi. Özellikle hız kontrol uygulamasında PID uygulaması yumuşak bir sönümle referans hıza geçilmesini sağladı. Kontrol sisteminin kaydettiği veriler, oluşturulan yazılımla değerlendirildi. Sistemin elektronik, kontrol ve yazılım bölümleri araçta kontrol edilmek istenen durumlara göre oluşturuldu. Tasarladığımız cihazı, maden işleme tesisinin yeraltında bulunan araçlarında test ettik. Aldığımız sonuçlara göre aracın diğer elektronik ve yazılımsal özelliklerine zarar vermemiştir. Aracın daha dikkatli kullanılmasına ve hız yapılmamasına kullanıcılar tarafından özen gösterilmiştir. Araç her yönü ile çok daha dikkatli kullanıldığından ve normalde dikkatten kaçan durumların cihaz tarafından uyarılmasından dolayı, aracın kullanım ömrü artmış ve bakım onarım maliyetleri çok büyük oranda düşmüştür.

Ayrıca aracın test edildiği işletmeden alınan veriler doğrultusunda bazı sonuçlar elde edilmiştir. Araç hız veri kayıtları incelenerek, aracı kullanan kişilerin aracı olumsuz yol koşullarında da yüksek hızda kullandıklarını tespit edip, hız kesici ile motor beyni ve diğer elektronik programlarını etkilemeyecek şekilde belirlediğimiz hızın üstüne çıkmasını engelledik. (Piyasadaki mevcut çalışmalarda yüksek hızlar için bu sistem var fakat $20 \mathrm{~km} / \mathrm{h}$ hız için yok). Bu hız kesici ve kaydedici sayesinde aracin hareket esnasında oluşan süspansiyon, makas, diferansiyeller, şanzıman gibi hareketli parçaların zarar görmesini engellenmiş olduk. Aracın gösterge panelinde olan bazı standart uyarı lambalarını çoğu kez kullananlar göremeyebiliyor. Bunlardan biri motor 1sı seviyesini gösteren hararet uyarı lambası veya göstergesi. Bu durumda motor hasarları çok yüksek maliyetlere çıkabiliyor. Bunu için motor sıcaklığı seviyesini sürekli kontrol eden sistemin, belirlenen sıcaklığın üzerine çıkması durumunda aracı kullanan kişiye sesli olarak uyarıda bulunmaktadır. Böylece hararete bağlı ağır motor hasarlarının yaşanması tamamen ortadan kaldırılmış oldu. Fren hidroliği herhangi bir şekilde eksildiğinde (fren borusu kırılması, çatlaması ya da bağlantı yerlerinden kaçırması) frenler tutmaz. Fren hidrolik seviyesinin belirlenen kritik seviyeye düşmesi durumunda, uyarı lambasının görülememe durumuna karşın, sesli uyarı sistemi uyarıda bulunmaktadır. $\mathrm{Bu}$ durumda maddi hasarlar ve yaralanmalı kazalar yaşanmadan tedbir almamız mümkün olur. Ek 
olarak yakıt alma sırasında unutulan depo kapağının takılmaması durumlarında; yakıt deposuna su, toz ve çamur kaçmasından dolayı komple yakıt sistemi arızası ya da hasarları oluşmaktaydı (depo, yakıt pompası, enjektörler, vb). Bu tip aksaklıklarda aracı kullanan kişiye sesli uyarı yapılarak bu gibi arızaların önüne geçilmiş olundu. Aracın direksiyon sıvısı (ATF) eksilmesi ya da bitmesi durumunda da maddi hasarlar meydana gelmektedir (direksiyon pompası ve direksiyon kutusu vb). Sesli uyarı sistemi ile bu tür aksaklıklar engellendi.

Cihazın kullanıldığı araçlarda kullanılmayan araçlara göre araç bakım masrafı açısından iki yıllık bir periyodun sonunda \%60 oranında bir tasarruf elde edildiği gözdendi. Tüm araçlara takılabilecek ve düşük hızlar dahil istenilen tüm hızlarda hız sabitlemesi yapabilen bu sistem "Samsun Teknopark" ta gerçekleştirildi. (Proje Kodu: 032248, Proje Adı: Araç ve Sürücü Kayıt Kontrol Sistemi)

\section{Kaynakça}

[1]. Wright, A.W., Switalski, G., Method and system for logging vehicle behavior, Patent No: US 9,311,271 B2, Date of Patent: 2016

[2]. Armitage, D.L, Kushnir, G.F., Mason, M.A., Driver performance analysis and consequence, Patent No: US 9,082,308 B2, Date of Patent: 2013

[3]. Schilling, S., Bartelt, J., Kuntz, M., Wagatha, H., Radio remote control system for controlling vehicle functions of a motor vehicle, Patent No: US 9,302,675 B2, Date of Patent: 2016

[4]. David, N.D., Ziskind, I., Systems devices and methods for vehicle speed control, Pub . No: US 2019 / 0064833 A1, Pub. Date: 2018

[5]. Sakaguchi, S., Shiomi, M., Kawade, H., Touhachi, H., Omori, M., Accelerator pedal depression force setting method for accelerator pedal depression force control device, US 8,977.462 B2, Date of Patent: 2015

[6]. Niino, H., Fukuda, S., Narita, T., Oooka, M., Vehicle control apparatus and vehicle control program, Patent No: US 9,731,719 B2, Date of Patent: 2017

[7]. Herndon, A., Systems and methods for driver and vehicle tracking, Patent No: US 9,648,579 B2, Date of Patent: 2017

[8]. Brookhuis, K.A., Waard, D., Janssen, W.H., Behavioural Impacts of Advanced Driver Assistance Systems an Overview, EJTIR, 2001, 245-253

[9]. Manoliu, A.V., Serbanescu, A., Trofimov, Y., Raginsky, A., Zheltov, S., Koponen, L., Schaminee, J., Methods and systems for generating horizon for use in an advanced driver assistance system (ADAS), Patent No.: US 9,726,505 B2, Date of Patent : 2017

[10]. Taylor, D.W., McCarthy, K.C., Lynam, N.R., Driver assist system for vehicle, Patent No.: US 8,543,330 B2, Date of Patent: 2013

[11]. Mukhtar, M., GPS based advanced vehicle tracking and vehicle control system, I.J. Intelligent Systems and Applications, 2015, 03, 1-12

[12]. Johnson, M.A., Moradi, M.H., PID control new identification and design methods, Springer, British Library Cataloguing in Publication Data, 2005

[13]. http://www.caglargul.com/2016/09/pid-kontrol-algoritmasi-ve-karakteristikleri.html 